\title{
A Comparison Reduction of 4-Nitrophenol by Gold Nanospheres and Gold Nanostars
}

\author{
Tao Ma, Wenshuo Yang, Simin Liu, Haijun Zhang and Feng Liang * \\ The State Key Laboratory of Refractories and Metallurgy, School of Chemistry \& Chemical Engineering, \\ Wuhan University of Science and Technology, Wuhan 430081, China; mataowust@163.com (T.M.); \\ ywsyangwenshuo@163.com (W.Y.); liusimin@wust.edu.cn (S.L.); zhanghaijun@wust.edu.cn (H.Z.) \\ * Correspondence: feng_liang@whu.edu.cn; Tel.: +86-27-6886-2107
}

Academic Editors: Alain Roucoux and Audrey Denicourt

Received: 12 December 2016; Accepted: 19 January 2017; Published: 24 January 2017

\begin{abstract}
In order to investigate structure-property relationships, the catalytic properties of gold nanoparticles were evaluated in the reduction of 4-nitrophenol by $\mathrm{NaBH}_{4}$. Using catalyst suspensions with identical amounts of gold, the following key results were obtained: first, the nanostars showed increased activity as compared to spherical gold nanoparticles; second, larger gold nanostars showed higher activity, likely because of the abundance of flat/spiky features on these particles, which show high metal utilization; third, treatment of the nanostar colloid with cucurbit[7]uril can be used to balance catalyst stability and activity; fourth, as expected from the decreasing surface atom fraction, the specific activity of the spherical nanoparticles decreased with increasing particle size.
\end{abstract}

Keywords: gold nanoparticles; gold nanostructures; reduction; cucurbiturils

\section{Introduction}

Over the last decade, noble metal nanoparticles (e.g., $\mathrm{Au}, \mathrm{Ag}$, Pd, and $\mathrm{Pt}$ ) have attracted enormous interest because of their unique advantages, such as excellent robustness, stability, and low-cost production with easy scale-up [1-6]. Among them, gold nanoparticles are extensively used in catalyzing diversified classes of reactions, including carbon monoxide oxidation, aerobic oxidation of alcohols and diols, carbon-carbon cross coupling reaction, and borohydride reductions [7-10]. The advantages of gold nanoparticles lie in their straightforward synthesis in different forms, stability, easily-controlled surface functionalization, and easy-to-handle immobilization on porous supports [7-10]. As a critical parameter, the size of the nanostructure typically controls the induction time and the rate of the reaction [11]. However, in the case of redox reactions, introducing sharp corners and edges to the shape of the nanocatalysts could further increase their catalytic efficiency because of the presence of surface atoms having unsatisfied valency that act as active sites [12-14].

Since the reduction of 4-nitrophenol (4-NP) to 4-aminophenol (4-AP) using excess sodium borohydride as a reducing agent only in the presence of metal nanostructures as catalysts was reported in 2002 [15,16], this model reduction has been used to study the catalytic efficiency of metal nanostructures with different shape, size, and composition [2]. It has mostly been suggested that gold nanoparticles could catalyze this reaction by facilitating electron transfer from $\mathrm{BH}_{4}{ }^{-}$to $4-\mathrm{NP}$ (Scheme 1), and the kinetics can be treated in terms of the Langmuir-Hinshelwood (LH) model [17,18]. A change in temperature does not drive a change in mechanism, thus allowing researchers to measure the activation energy of the reaction. 


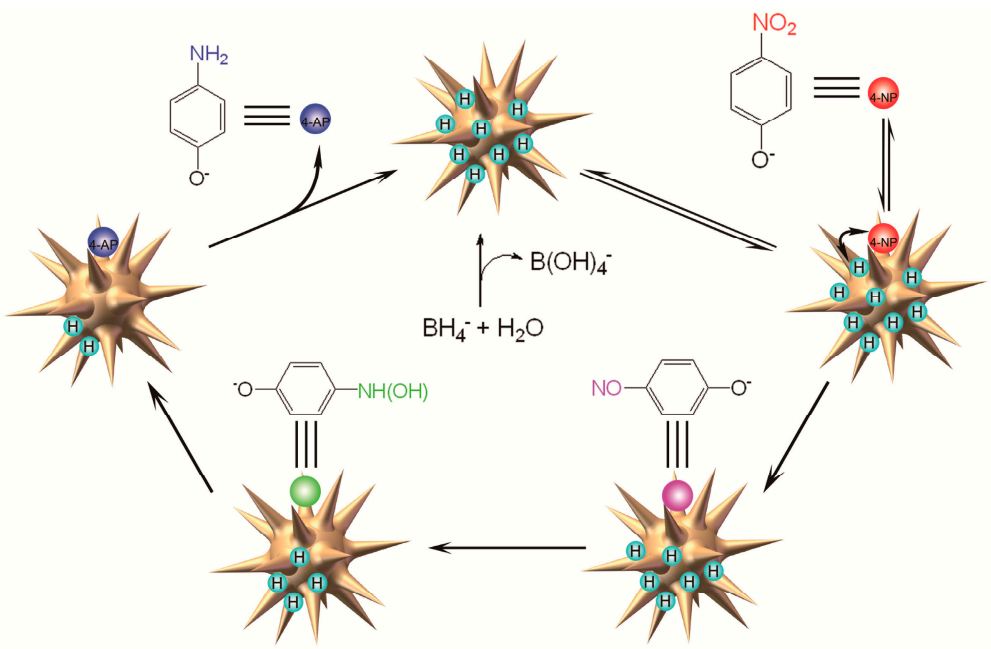

Scheme 1. The proposed reduction of 4-nitrophenol (4-NP) to 4-aminophenol (4-AP) catalyzed by gold nanostars (Au-NSs) in the presence of $\mathrm{NaBH}_{4}$.

Branched and higher surface area substructured nanostructures can improve the performance of Au nanomaterials in many fields [14]. For instance, the branched structure leads to high electromagnetic field enhancements, and presents a strategy to prepare hot spots for surface-enhanced Raman spectroscopy [3]. Although several synthetic techniques for the production of high surface area substructured gold nanomaterials—such as galvanic replacement for spongy gold nanotubes [4] or the electrodeposition of spiky gold nanodendrites [5] — have been developed, a small number of gold nanostars was prepared with a seed-mediated colloidal approach and further applied in catalyzing the reduction of 4-nitrophenol (4-NP) to 4-aminophenol (4-AP) [6].

Our long-term goal is to construct functional nanomaterials for emerging catalytic and biological applications [19-22]. In our previous works, we developed Au-based bi-, and tri-metallic nanoclusters, which are one of the most effective catalysts for aerobic glucose oxidation [23-25]. Recently, we achieved high cargo loading and controlled release with gold nanostars modified with cucurbit $[n]$ urils $(\mathrm{CB}[n])[26]$, and established a colorimetric sensor for sensitive and selective sensing of copper(II) ions based on thiol etching of gold nanoclusters [27]. The primary goal of this work is to quantitatively evaluate the catalytic properties of gold nanospheres (Au-NPs) and nanostars (Au-NSs) reported previously with different size, shape, and stabilizer in our group, because the correlation between catalytic properties and physicochemical properties (e.g., morphologies and sizes) of nanomaterials always draws increased interest [12-14].

\section{Results and Discussion}

Au-NPs of 4, 16, 40, and $80 \mathrm{~nm}$ diameter were prepared by following seeded growth method [28]; $\mathrm{Au}-\mathrm{NSs}$ of 40 and $117 \mathrm{~nm}$ (with and without capped CB[7]) diameter were prepared by our reported method [26]. It could control particle size by varying the ratio of seed to metal salt. The resulting particles solution was centrifuged and washed several times and then redispersed in double distilled water for further application. The content of $\mathrm{Au}$ in the samples was measured by using inductively coupled plasma optical emission spectroscopy (ICP-OES, Table S1). Structural analysis of the synthesized nanoparticles has been characterized by transmission electron microscopy (TEM, Figure 1). Absorption spectra of the as-synthesized gold nanoparticles were taken at room temperature with a Shimadzu UV-3600 UV-vis-NIR (ultraviolet-visible-near infrared) spectrometer. The red shifting of the absorption band of nanoparticle is observed with increasing core size and protrusion lengths, which is consistent with previous results (Figure S1) [26,28,29]. 

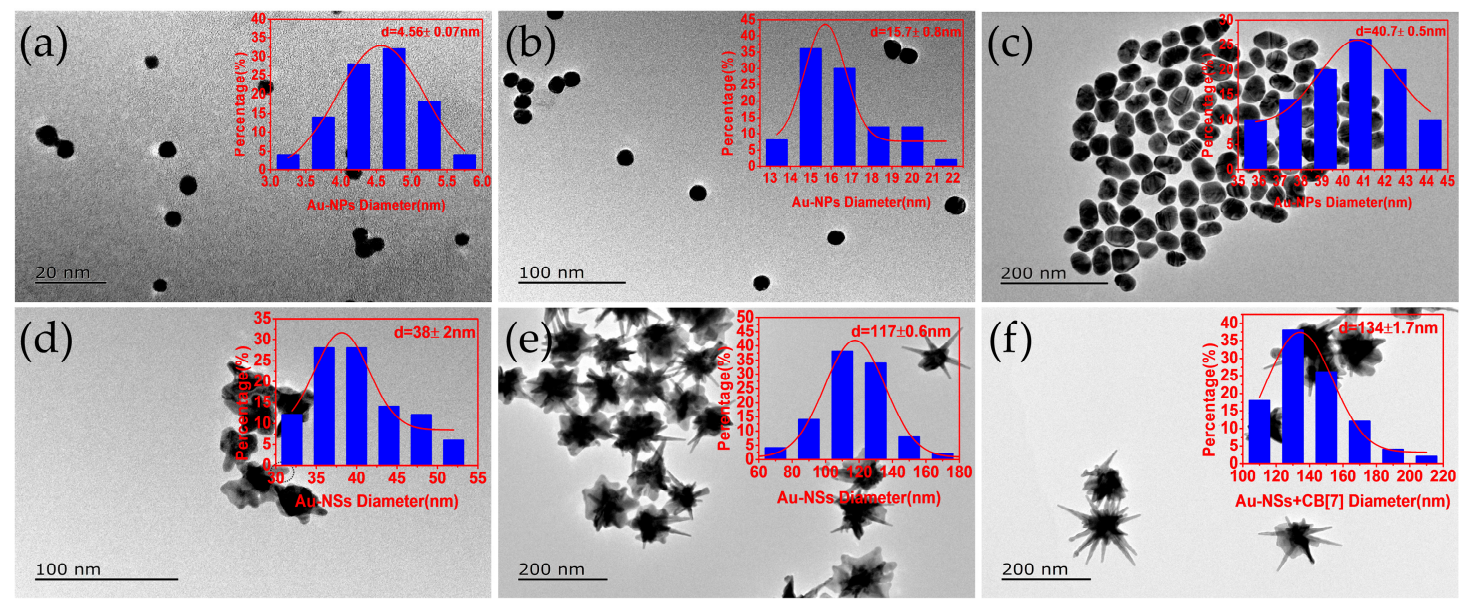

Figure 1. Typical transmission electron microscopy (TEM) images of synthesized gold nanoparticles in this work: (a) $4 \mathrm{~nm}$ gold nanospheres (Au-NPs); (b) $16 \mathrm{~nm} \mathrm{Au-NPs;} \mathrm{(c)} 40 \mathrm{~nm} \mathrm{Au-NPs;} \mathrm{(d)} 40 \mathrm{~nm}$ Au-NSs; (e) $117 \mathrm{~nm}$ Au-NSs; (f) $134 \mathrm{~nm}$ Au-NSs + CB[7] (cucurbit[7]uril). The microstructures were characterized by TEM (JEM-2010 UHR, JEOL, Tokyo, Japan).

The effect of Au-NP particle size on the reaction of 4-NP with $\mathrm{NaBH}_{4}$ to form 4-AP was firstly examined. With the addition of the catalyst nanoparticles to the reaction mixture containing 4-NP and $\mathrm{NaBH}_{4}$, an evolution of a new peak for 4-AP at $\sim 305 \mathrm{~nm}$ and a gradual decrease in the characteristic absorption peak of 4-NP at $400 \mathrm{~nm}$ was observed (Figure S1) [2]. It could be easily found that the peak intensity at $400 \mathrm{~nm}$ markedly decreased with the prolonging of the reaction time. As shown in Figure 2c, it took merely 2 min to completely convert 4-NP to 4-AP in the presence of $4 \mathrm{~nm}$ Au-NPs at room temperature $\left(24^{\circ} \mathrm{C}\right)$. After the same amount of $16 \mathrm{~nm}$ and $40 \mathrm{~nm}$ Au-NPs were used as the catalyst, they took almost 12 and over $15 \mathrm{~min}$ to complete the conversion of 4-NP to 4-AP. A similar trend was also observed at a lower or higher temperature; for example, 16 and $43{ }^{\circ} \mathrm{C}$, respectively (see Figure 2a,e). Namely, $4 \mathrm{~nm}$ nanoparticles bore the strongest catalytic activity, then $16 \mathrm{~nm}$ nanoparticles, and finally $40 \mathrm{~nm}$ nanoparticles in the case of gold nanospheres under the tested conditions.

To understand the impact of the morphologies of gold nanoparticles on the catalysis of 4-NP to 4-AP, we also investigated the catalytic activities of Au-NSs. While Au-NSs were employed, the reduction of 4-NP to 4-AP could be finished within $1.5 \mathrm{~min}$ by $40 \mathrm{~nm}$ Au-NSs and within $0.6 \mathrm{~min}$ by $117 \mathrm{~nm}$ Au-NSs at room temperature (see Figure 2d). Obviously, the catalytic activities of catalysts significantly increased with increasing core size and protrusion lengths. In the nanostars (see Figure 2e,f), there seem to be leaf-like structures present aside the spikes, which could be expected to have an improved exposure of Au atoms (as compared to the spherical particles), and need to be confirmed in further investigation [12-14].

The stability is a common issue in the application of nanoparticles as a catalyst, as the nanoparticles tend to aggregate and lead to gradual reduction in catalytic activity [30]. In the following study, the $\mathrm{CB}[7]$ was used for the stabilization of gold nanoparticles because cucurbit[ $n]$ urils have a good affinity for gold, and could prevent the aggregation [26]. Although CB[7]-capped Au-NSs could be stabilized in solution for weeks, the undesired decrease of the catalytic efficiency of Au-NSs capped with CB[7] could be observed. It is possibly due to surface coverage by cucurbiturils, which occupies active surface sites and hinders the diffusion of reactant molecules toward the nanoparticles [31,32]. 
(a)

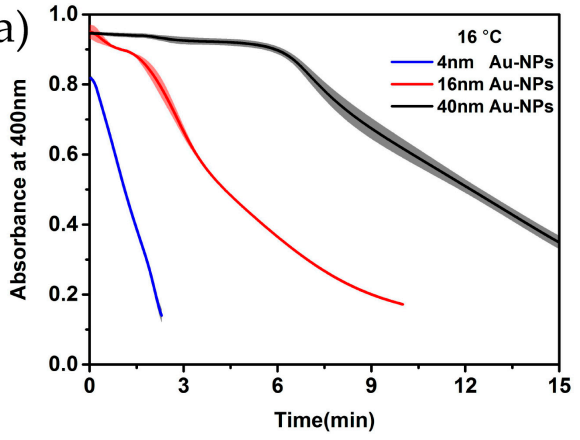

(C)

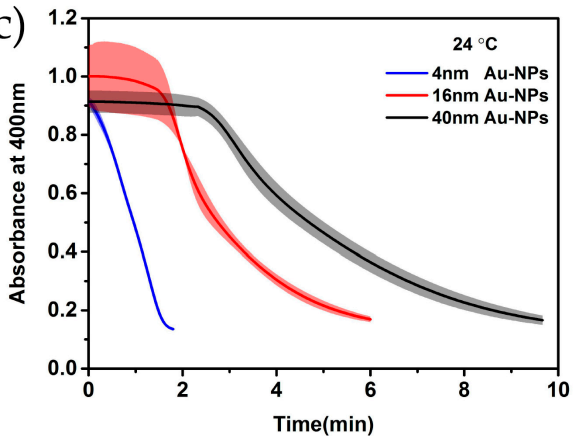

(e)

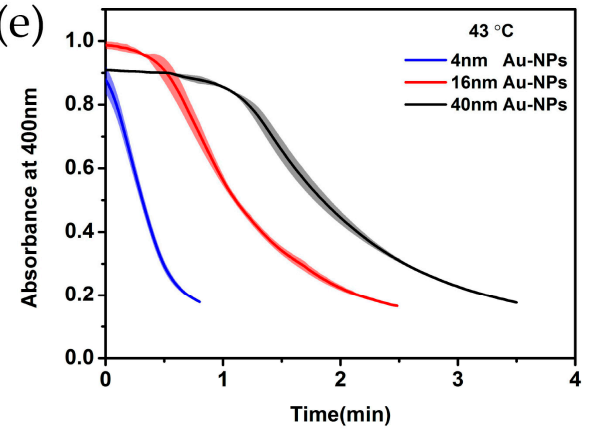

(b)

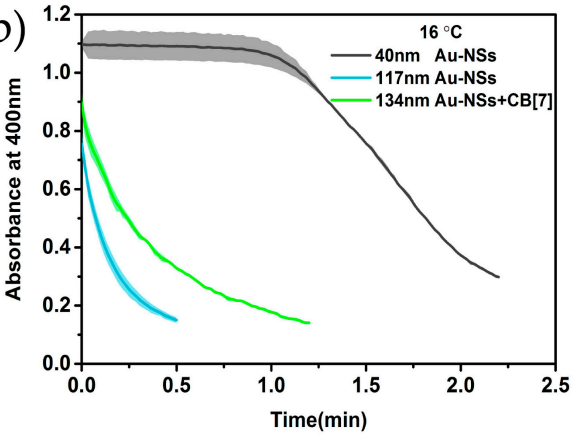

(d)

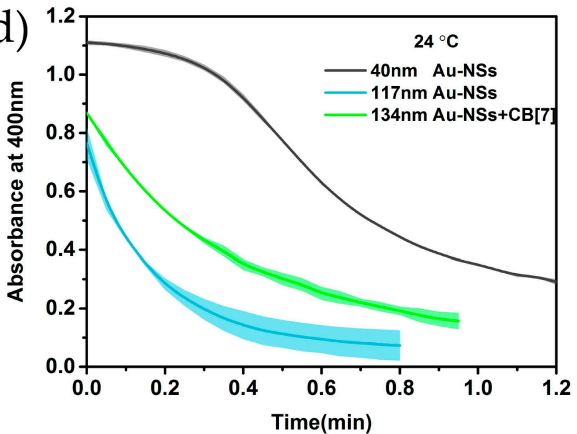

(f)

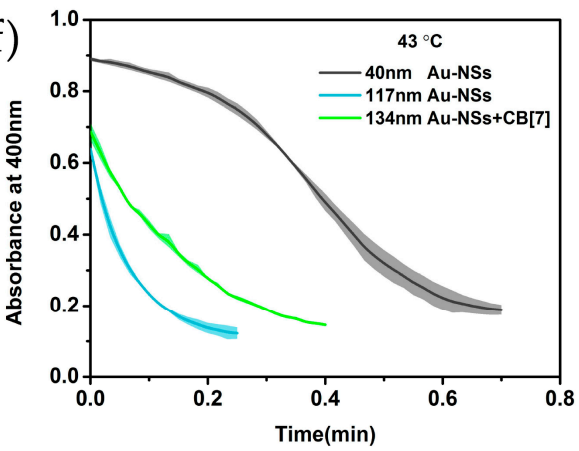

Figure 2. The peak intensity at $400 \mathrm{~nm}$ for 4-NPas a function of time at three different temperatures in the presence of: (a) Au-NPs at $16{ }^{\circ} \mathrm{C}$; (b) Au-NSs at $16{ }^{\circ} \mathrm{C}$; (c) Au-NPs at $24{ }^{\circ} \mathrm{C}$; (d) Au-NSs at $24{ }^{\circ} \mathrm{C}$, (e) Au-NPs at $43{ }^{\circ} \mathrm{C}$, and (f) Au-NSs at $43{ }^{\circ} \mathrm{C}$. In all cases, the concentrations of 4 -NP and $\mathrm{NaBH}_{4}$ were $7 \times 10^{-5}$ and $2.1 \times 10^{-2} \mathrm{M}$, respectively, and the concentration of Au-based catalyst was $\sim 8.89 \mathrm{mg} / \mathrm{L}$ of Au atoms. The error bars represent standard deviations obtained from three or more trials. The absorption spectra were acquired with a UV-3600 UV-vis-NIR (ultraviolet-visible-near infrared) spectrometer (Shimadzu, Kyoto, Japan).

In the present work, the reduction of 4-NP to 4-AP could be reasonably assumed as a pseudo-first-order kinetics regarding 4-NP, owing to the presence of excess $\mathrm{NaBH}_{4}$ in the experiment $[2,33]$. By measuring the absorbance $(A)$ of absorption peak of 4-NP at $400 \mathrm{~nm}$ with reaction time and plotting $\ln \left(A_{o} / A_{t}\right)$ versus reaction time $(t)$, the apparent reaction rate constant $\left(k_{\text {app }}\right)$ was calculated. As shown in Figure S3, a linear relationship between $\ln \left(A_{0} / A_{t}\right)$ and reaction time $(t)$ was obtained for all the catalysts, indicating that the reaction is first-order with respect to 4-NP. The apparent rate constants were measured from the slope of the lines, and the values are summarized in Figure 3 and Table 1. The induction time and apparent rate constant for $40 \mathrm{~nm} \mathrm{Au-NSs}$ at room temperature were $0.32 \mathrm{~min}$ and $1.776 \mathrm{~min}^{-1}$, and for $40 \mathrm{~nm} \mathrm{Au-NPs} \mathrm{they} \mathrm{were} 2.8 \mathrm{~min}$ and $0.234 \mathrm{~min}^{-1}$. These induction time values indicate that 4-NP catalysis initiates rapidly on Au-NSs relative to $\mathrm{Au}-\mathrm{NPs}$; the $k_{\mathrm{app}}$ values indicate that the reaction proceeds nearly eight times faster on 
$\mathrm{Au}-\mathrm{NSs}$ than on Au-NPs. In general, the higher the $k_{\mathrm{app}}$, the faster the catalytic reaction and the higher the efficiency of the nanocatalyst utilized. In our case, Au-NSs exhibited stronger catalytic activity than that of Au-NPs, which suggests that the corresponding surface area of metal nanoparticles influences the adsorption of the reactants and plays a dominant role in the reaction rate [2]. The considerable enhancement in catalytic activity for the Au-NSs can probably be attributed to their higher surface area-to-volume ratio of multi-branched nanostructures.

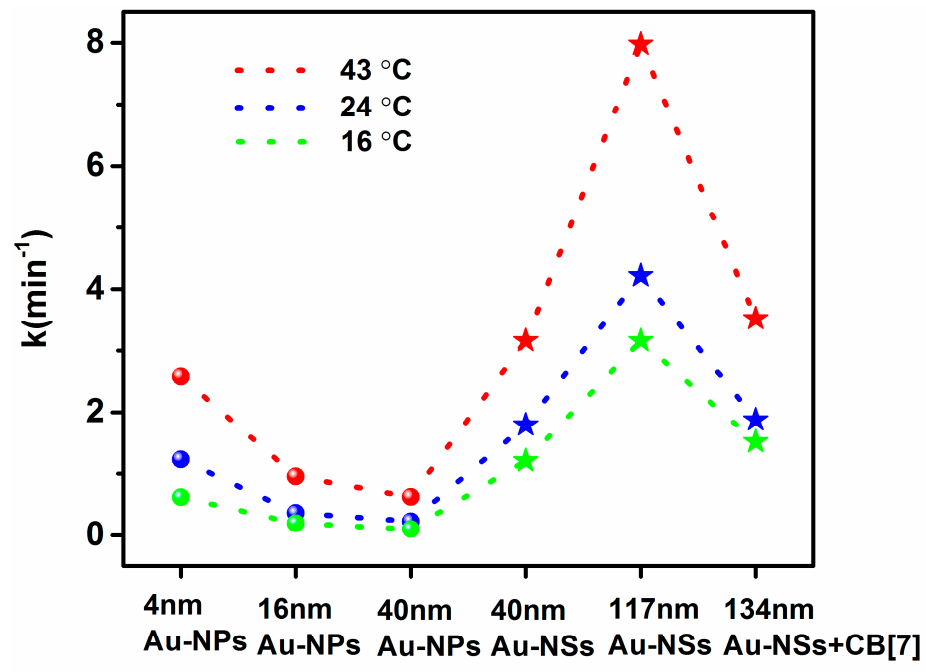

Gold Nanostructures

Figure 3. The apparent reaction rate constant $\left(k_{\mathrm{app}}\right)$ obtained from the linear fit of 4-NP catalysis over time.

Table 1. Summary of the apparent rate constant $\left(k_{\text {app }}\right)$, induction time $\left(t_{0}\right)$ at three different temperatures, and the apparent activation energies $\left(E_{\mathrm{a}}\right)$ for gold nanoparticles in this work.

\begin{tabular}{|c|c|c|c|c|c|c|c|}
\hline \multirow{2}{*}{ Nanoparticles } & \multicolumn{2}{|c|}{$16^{\circ} \mathrm{C}$} & \multicolumn{2}{|c|}{$24^{\circ} \mathrm{C}$} & \multicolumn{2}{|c|}{$43^{\circ} \mathrm{C}$} & \multirow{2}{*}{$E_{a}(\mathrm{~kJ} / \mathrm{mol})$} \\
\hline & $k_{\text {app }}\left(\min ^{-1}\right)$ & $t_{0}(\min )$ & $k_{\text {app }}\left(\min ^{-1}\right)$ & $t_{0}(\min )$ & $k_{\text {app }}\left(\min ^{-1}\right)$ & $t_{0}(\min )$ & \\
\hline $4 \mathrm{~nm} \mathrm{Au}-\mathrm{NPs}$ & $0.621 \pm 0.007$ & $-a^{a}$ & $1.247 \pm 0.031$ & - & $2.590 \pm 0.041$ & - & $38.690 \pm 7.408$ \\
\hline $\begin{array}{l}16 \mathrm{~nm} \\
\mathrm{Au}-\mathrm{NPs}\end{array}$ & $0.198 \pm 0.002$ & $2.5 \pm 0.3$ & $0.363 \pm 0.019$ & $1.8 \pm 0.2$ & $0.950 \pm 0.013$ & $0.5 \pm 0.05$ & $43.566 \pm 1.713$ \\
\hline $\begin{array}{l}40 \mathrm{~nm} \\
\mathrm{Au}-\mathrm{NPs}\end{array}$ & $0.101 \pm 0.013$ & $6.4 \pm 0.42$ & $0.234 \pm 0.026$ & $2.8 \pm 0.67$ & $0.628 \pm 0.040$ & $1.1 \pm 0.12$ & $49.461 \pm 7.54$ \\
\hline $\begin{array}{l}40 \mathrm{~nm} \\
\mathrm{Au}-\mathrm{NSs}\end{array}$ & $1.207 \pm 0.015$ & $1.2 \pm 0.17$ & $1.776 \pm 0.080$ & $0.32 \pm 0.27$ & $3.134 \pm 0.107$ & $0.15 \pm 0.05$ & $26.448 \pm 0.557$ \\
\hline $\begin{array}{l}117 \mathrm{~nm} \\
\mathrm{Au}-\mathrm{NSs} \\
134 \mathrm{~nm}\end{array}$ & $3.145 \pm 0.040$ & - & $4.364 \pm 0.152$ & - & $7.968 \pm 0.325$ & - & $26.093 \pm 0.111$ \\
\hline $\begin{array}{l}\text { Au-NSs + } \\
\text { CB[7] }\end{array}$ & $1.517 \pm 0.152$ & - & $1.850 \pm 0.073$ & - & $3.526 \pm 0.100$ & - & $24.042 \pm 1.621$ \\
\hline
\end{tabular}

The $k_{\text {app }}$ values were then correlated to the inverse temperature, and we calculated the apparent activation energies $\left(E_{\mathrm{a}}\right)$ based on the Arrhenius equation (Figure S4 and Table 1) [13,33]. A notable difference in $E_{\mathrm{a}}$ was observed for both morphologies. The $E_{\mathrm{a}}$ for Au-NSs was around $26 \mathrm{~kJ} / \mathrm{mol}$, which is significantly lower than the $E_{\mathrm{a}}$ for the Au-NPs at $\sim 40 \mathrm{~kJ} / \mathrm{mol}$. The result of a lower value of $E_{\mathrm{a}}$ for $\mathrm{Au}-\mathrm{NSs}$ relative to Au-NPs can be attributed to more efficient reactants accessibility of multiple sharp branched gold surface relative to those with smooth surfaces, owing to their high surface area-to-volume ratios [34,35]. This follows the trend previously described, whereby the catalyst with higher surface-to-volume ratios has more dangling-bonds as activity sites on the surface, and will therefore be more active in promoting catalytic conversion [12-14,36]. The inclusion of Ag in the nanostars as a second metal could be detected (Table S1 and Figure S5), and could also contribute to the improved catalytic activity $[16,23-25,31]$. The effect of the second metal in the catalysis will be extensively explored in our on-going project. 
Compared with some previously reported anisotropic gold nanoparticles [2,37-42], the present gold nanostars (with $k_{\mathrm{app}}=4.36 \mathrm{~min}^{-1}$ ) presented better catalytic activity than that of gold nanocages (with $k_{\mathrm{app}}=2.83 \mathrm{~min}^{-1}$ ) [33] and gold nanoantennas (with $k_{\mathrm{app}}=1.61 \mathrm{~min}^{-1}$ ) [13] for the reduction of 4-NP at room temperature. Moreover, compared with some previously reported gold nanoparticles capped with macrocycles (e.g., cyclodextrin, calixarene, and cucurbiturils) [32,43,44], cucurbituril-capped gold nanostars also presented close or better catalytic activity for the reduction of 4-NP $\left(k_{\text {app }}=1.85 \mathrm{~min}^{-1}\right.$, see Table 2$)$. In particular, the cucurbiturils-a group of cyclic pumpkin-shaped molecules composed of $n$ glycoluril units $(n=5-8,10,14)$ bridged by methylene groups-could assemble gold nanoparticles by carbonyl-fringed portals, which is very important in further practical application [45].

Table 2. Comparison of 4-NP reduction by various gold nanoparticles from the literature and this work at room temperature.

\begin{tabular}{|c|c|c|c|c|}
\hline Catalyst (mg) a & Particle Size (nm) & $\underset{\text { (mole ratio) }}{\mathrm{NaBH}_{4} / 4-\mathrm{NP} / \mathrm{Au}}$ & $k_{\text {app }}\left(\min ^{-1}\right)$ & Ref. \\
\hline Au-nanocages $/ 0.08 \mathrm{mg}$ & 50 & $1035 / 3.45 / 1$ & 2.83 & [33] \\
\hline Au-nanoboxes $/ 0.08 \mathrm{mg}$ & 50 & $1035 / 3.45 / 1$ & 1.12 & [33] \\
\hline Partially hollow Au-nanoboxes/0.08 mg & 50 & $1035 / 3.45 / 1$ & 0.59 & [33] \\
\hline Au-solid nanoparticles $/ 0.08 \mathrm{mg}$ & 50 & $1035 / 3.45 / 1$ & 0.20 & [33] \\
\hline Au-solid nanoparticles $/ 0.08 \mathrm{mg}$ & 5 & $1035 / 3.45 / 1$ & 0.95 & [33] \\
\hline$[\mathrm{Au}] /[$ protein $] / 0.00532 \mathrm{mg}$ & $-b$ & $18,518 / 0.463 / 1$ & 0.39 & [37] \\
\hline Dimethylformamide-stabilized Au-NCs & $<2$ & $200,000 / 100 / 1$ & 0.18 & [38] \\
\hline $\mathrm{Au}-\mathrm{NPs} / \mathrm{CeO}_{2} / 10 \mathrm{mg}$ & - & $462 / 11 / 1$ & 0.13 & [39] \\
\hline Au-NPs@SiO 2 & 104 & $750 / 2.1 / 1$ & 0.84 & [40] \\
\hline Au-NPs-Carbon Dots & 4 & $10.56 / 0.192 / 1$ & 0.68 & [41] \\
\hline $\mathrm{Au}-\mathrm{Cu}$ alloy nanocrystals $/ 0.1 \mathrm{mg}$ & 45 & - & 2.56 & [42] \\
\hline $\mathrm{Au}-\mathrm{Cu}$ nanorod networks $/ 0.1 \mathrm{mg}$ & 100 & - & 0.07 & [42] \\
\hline $\mathrm{Au}-\mathrm{Cu}$ nanopolyhedrons $/ 0.1 \mathrm{mg}$ & 50 & - & 0.04 & [42] \\
\hline Au nanocrystals $/ 0.1 \mathrm{mg}$ & 5 & - & 1.98 & [42] \\
\hline $\begin{array}{l}\alpha \text {-Cyclodextrin-capped Au } \\
\text { nanoparticles } / 0.0118 \mathrm{mg}\end{array}$ & 11 & $250 / 5.67 / 1$ & 0.28 & [43] \\
\hline $\begin{array}{l}\alpha \text {-Cyclodextrin-capped Au } \\
\text { nanoparticles } / 0.0118 \mathrm{mg}\end{array}$ & 20 & $250 / 5.67 / 1$ & 0.21 & [43] \\
\hline $\begin{array}{c}\alpha \text {-Cyclodextrin-capped Au } \\
\text { nanoparticles } / 0.0118 \mathrm{mg}\end{array}$ & 26 & $250 / 5.67 / 1$ & 0.18 & [43] \\
\hline $\begin{array}{c}\text { Calix[6]arene phosphine-modified Au } \\
\text { nanoparticles } / 0.03 \mathrm{mg}\end{array}$ & 4 & $360 / 2 / 1$ & 4.3 & [32] \\
\hline $\begin{array}{l}\text { Calix[4]arenethiol-modified } \mathrm{Au} \\
\text { nanoparticles } / 0.03 \mathrm{mg}\end{array}$ & 4 & $360 / 2 / 1$ & 0.92 & [32] \\
\hline $\mathrm{CB}[7]-$ protected AuNPs $/ 0.3 \mathrm{mg}$ & 10 & $10 / 0.23 / 1$ & 0.16 & [44] \\
\hline Au-NPs/0.0056 mg & 4 & $516 / 1.72 / 1$ & 1.25 & ${ }^{c} \mathrm{C}$ \\
\hline $\mathrm{Au}-\mathrm{NPs} / 0.0056 \mathrm{mg}$ & 16 & $516 / 1.72 / 1$ & 0.36 & c \\
\hline $\mathrm{Au}-\mathrm{NPs} / 0.0056 \mathrm{mg}$ & 40 & $516 / 1.72 / 1$ & 0.23 & c \\
\hline $\mathrm{Au}-\mathrm{NSs} / 0.0056 \mathrm{mg}$ & 40 & $516 / 1.72 / 1$ & 1.78 & c \\
\hline Au-NSs $/ 0.0056$ mg & 117 & $516 / 1.72 / 1$ & 4.36 & c \\
\hline $\mathrm{Au}-\mathrm{NPs}+\mathrm{CB}[7] / 0.0056 \mathrm{mg}$ & 134 & $516 / 1.72 / 1$ & 1.85 & c \\
\hline
\end{tabular}

a In this column the "Catalyst (mg)" indicates the amounts of catalyst (including the stabilizer or supports and the metals); ${ }^{\mathrm{b}}$ Not determined; ${ }^{\mathrm{c}}$ This work.

\section{Materials and Methods}

\subsection{Synthesis of $40 \mathrm{~nm} \mathrm{Au}-\mathrm{NSs}$}

A typical synthesis of Au-NSs of $40 \mathrm{~nm}$ : $555.5 \mathrm{mg}$ of poly(N-vinylpyrrolidone) (PVP) was added to an aqueous solution of $\mathrm{HAuCl}_{4}(1 \mathrm{mM}, 50 \mathrm{~mL})$, in which the molar ratio of $\mathrm{AuCl}_{4}{ }^{-}$and monomer unit of PVP was kept at 1:100. An aqueous solution of $\mathrm{NaBH}_{4}(100 \mathrm{mM}, 5 \mathrm{~mL})$ was rapidly sprayed into the mixture under vigorous stirring $(500 \mathrm{rpm}$ ) after the mixture was further stirred for $30 \mathrm{~min}$ in a bath kept at $0{ }^{\circ} \mathrm{C}$. The color change from pale yellow to dark brown indicated the formation of $\mathrm{Au}-\mathrm{NPs}$ with small size. In order to remove inorganic impurities such as $\mathrm{Na}^{+}$and $\mathrm{Cl}^{-}$(and thus enhance the stability of the small Au-NPs against coalescence), the Au:PVP NPs were subsequently dialyzed overnight. The produced dialyzed hydrosol, as seed solution, was diluted and stored at $4{ }^{\circ} \mathrm{C}$. Then, the solutions of $\mathrm{HCl}(1 \mathrm{M}, 600 \mu \mathrm{L})$ and silver nitrate $(0.01 \mathrm{M}, 600 \mu \mathrm{L})$ were successively added to $60 \mathrm{~mL}$ of chloroauric acid $(0.25 \mathrm{mM})$ at room temperature under moderate stirring $(500 \mathrm{rpm})$ for $30 \mathrm{~s}$ to obtain the growth solution. Then, $900 \mu \mathrm{L}$ of seed solution was added to the growth solution in an ice bath. After the mixture solution recovered to room temperature, $700 \mu \mathrm{L}$ of ascorbic acid $(0.1 \mathrm{M})$ 
was added. After stirring for $60 \mathrm{~s}$, the color gradually turned from light brown to dark blue, and the colloidal solution of $40 \mathrm{~nm}$ Au-NSs was produced.

\subsection{Catalysis Studies}

$35 \mu \mathrm{L}$ of 4-nitrophenol (4-NP, $\left.1.4 \times 10^{-3} \mathrm{M}\right)$ solution was added to quartz cuvette $(1 \mathrm{~mL})$. The color of the solution changed from colorless to bright yellow immediately when $35 \mu \mathrm{L}$ of $\mathrm{NaBH}_{4}$ solution was added. Then, $630 \mu \mathrm{L}$ solutions containing the same concentration of $\mathrm{Au}$ atoms $(\sim 8.89 \mathrm{mg} / \mathrm{L})$ was added from stock solutions, and the mixture was stirred for a few seconds (we measured the concentration of Au atoms in the different solutions of gold nanostructures as in Table S1, and then the stock solutions were prepared to maintain the same concentration of $\mathrm{Au}$ atoms $(\sim 8 \mathrm{mg} / \mathrm{L})$ during the catalytic reaction). Finally, the absorbance spectra and the curves of absorbance versus time at $400 \mathrm{~nm}$ was continuously measured for the mixed solution.

\section{Conclusions}

In the present study, different gold nanoparticle colloids were prepared using convenient reduction reactions. Spherical particles were prepared in the presence of PVP, which served as seeds for nanostars, which were obtained by anisotropic overgrowth. The catalytic activity of differently-sized nanospheres and nanostars - the latter also in a protected variety-were compared using a model reaction (nitrophenol reduction by borohydride). As a main result, the nanostars showed a distinct performance improvement over the spherical particles.

Nanostars are interesting not only for catalysis, but for various fields-perhaps most prominently plasmonics. Gold nanostar synthesis usually requires cationic surfactants [14]. In this work, the controlled synthesis of gold nanospheres and gold nanostars with adjustable sizes was realized by seed-mediated growth. The nanostars were obtained with $\mathrm{AgNO}_{3}$ and $\mathrm{HCl}$, and have interesting morphological features such as high aspect ratio spikes. Silver (I) or halide ions are known to play an important role in Au nanoparticle shape control, such as in electroless plating of spiky Au films [46] or the colloidal synthesis of faceted particles [47]. $\mathrm{Ag}^{+}$and $\mathrm{Cl}^{-}$possibly played a similar role in our synthesis of nanostars, and their effects need to be further investigated.

Despite their interesting properties, there is a lack of catalytic studies on metal nanostars. In this field, this work provides activity values normalized to the number of gold atoms, so the utilization of the noble metal by the different catalysts can be conveniently compared. Additionally, the activity investigation is supported by an analysis of the activation energies and the induction periods. The nanostars show increased activity as compared to spherical gold nanoparticles. Treatment of the nanostar colloid with cucurbit[7]uril can be used to balance catalyst stability and activity, which could be further utilized in practical applications.

Supplementary Materials: The following are available online at www.mdpi.com/2073-4344/7/2/38/s1, Table S1: Concentration of $\mathrm{Au} / \mathrm{Ag}$ atoms in different colloidal solution of Gold nanostructures; Figure S1: UV-vis-NIR absorption spectra of gold nanoparticles in this work. The absorption spectra were acquired with a UV-3600 UV-vis-NIR spectrometer (Shimadzu, Kyoto, Japan); Figure S2: Typical UV-vis absorption spectra of the systems containing 4-NP and $\mathrm{NaBH}_{4}$ in the presence of gold nanostructures for various durations. The absorption spectra were acquired with a UV-3600 UV-vis-NIR spectrometer (Shimadzu, Kyoto, Japan); Figure S3: The relationships between $\ln \left(A_{\mathrm{o}} / A_{t}\right)$ and the reaction time at three different temperatures; Figure S4: The Arrhenius plots for reactions catalyzed by (a) Au-NPs, (b) Au-NSs. The apparent activation energy $\left(E_{\mathrm{a}}\right)$ can be calculated from the slope of the linear fitting in each case; Figure S5: Representative high-resolution transmission electron microscopy TEM (HRTEM) image of gold nanostars (Au-NSs), which clearly shows the presence of Au and Ag atoms.

Acknowledgments: We acknowledge the financial support from National Natural Science Foundation of China (21372183), Thousand Youth Talents Program, Wuhan Applied Basic Research Programs of China (2015060101010069), and the Open Funds of the State Key Laboratory of Electroanalytical Chemistry (SKLEAC201609).

Author Contributions: T.M. and F.L. conceived and designed the experiments; T.M. and W.Y. performed the experiments; T.M. and F.L. analyzed the data; S.L. and H.Z. contributed reagents/materials/analysis tools; T.M. and F.L. wrote the paper. 
Conflicts of Interest: The authors declare no conflict of interest.

\section{References}

1. Henglein, A. Small-particle research: Physicochemical properties of extremely small colloidal metal and semiconductorparticles. Chem. Rev. 1989, 89, 1861-1873. [CrossRef]

2. Zhao, P.; Feng, X.; Huang, D.; Yang, G.; Astruc, D. Basic concepts and recent advances in nitrophenol reduction by gold- and other transition metal nanoparticles. Coord. Chem. Rev. 2015, 287, 114-136. [CrossRef]

3. Bedford, E.E.; Boujday, S.; Pradierab, C.-M.; Gu, F.X. Nanostructured and spiky gold in biomolecule detection: Improving binding efficiencies and enhancing optical signals. RSC Adv. 2015, 5, 16461-16475. [CrossRef]

4. Muench, F.; Rauber, M.; Stegmann, C.; Lauterbach, S.; Kunz, U.; Kleebe, H.-J.; Ensinger, W. Ligand-optimized electroless synthesis of silver nanotubes and their activity in the reduction of 4-nitrophenol. Nanotechnology 2011, 22, 415602. [CrossRef] [PubMed]

5. Lv, Z.-Y.; Mei, L.-P.; Chen, W.-Y.; Feng, J.-J.; Chen, J.-Y.; Wang, A.-J. Shaped-controlled electrosynthesis of gold nanodendrites for highlyselective and sensitive SERS detection of formaldehyde. Sens. Actuators B Chem. 2014, 201, 92-99. [CrossRef]

6. De Oliveira, F.M.; de Araújo Nascimento, L.R.B.; Calado, C.M.S.; Meneghetti, M.R.; da Silva, M.G.A. Aqueous-phase catalytic chemical reduction of $p$-nitrophenol employing soluble gold nanoparticles with different shapes. Catalysts 2016, 6, 215. [CrossRef]

7. Thompson, D.T. Catalytically highly active top gold atom on palladium nanocluster. Nano Today 2007, 2, 40-43. [CrossRef]

8. Stratakis, M.; Garcia, H. Catalysis by supported gold nanoparticles: Beyond aerobic oxidative processes. Chem. Rev. 2012, 112, 4469-4506. [CrossRef] [PubMed]

9. Mikami, Y.; Dhakshinamoorthy, A.; Alvaro, M.; García, H. Catalytic activity of unsupported gold nanoparticles. Catal. Sci. Technol. 2013, 3, 58-69. [CrossRef]

10. Scholder, P.; Hafner, M.; Hassel, A.W.; Nischang, I. Gold nanoparticle@polyhedraloligomericsilsesquioxane hybrid scaffolds in microfluidic format-Highly efficient and green catalytic platforms. Eur. J. Inorg. Chem. 2016, 7, 951-955. [CrossRef]

11. Murzin, D.Y. Nanokinetics for nanocatalysis. Catal. Sci. Technol. 2011, 1, 380-384. [CrossRef]

12. Mahmoud, M.A.; Narayanan, R.; El-Sayed, M.A. Enhancing colloidal metallic nanocatalysis: Sharp edges and corners for solid nanoparticles and cage effect for hollow ones. Acc. Chem. Res. 2013, 46, 1795-1805. [CrossRef] [PubMed]

13. Soetan, N.; Zarick, H.F.; Banks, C.; Webb, J.A.; Libson, G.; Coppola, A.; Bardhan, R. Morphology-directed catalysis with branched gold nanoantennas. J. Phys. Chem. C 2016, 120, 10320-10327. [CrossRef]

14. Guerrero-Martínez, A.; Barbosa, S.; Pastoriza-Santos, I.; Liz-Marzán, L.M. Nanostars shine bright for you: Colloidal synthesis, properties and applications of branched metallic nanoparticles. Curr. Opin. Colloid Interface Sci. 2011, 16, 118-127. [CrossRef]

15. Pradhan, N.; Pal, A.; Pal, T. Silver nanoparticle catalyzed reduction of aromatic nitro compounds. Colloids Surf. A 2002, 196, 247-257. [CrossRef]

16. Esumi, K.; Miyamoto, K.; Yoshimura, T. Comparison of PAMAM-Au and PPI-Au nanocomposites and their catalytic activity for reduction of 4-Nitrophenol. J. Colloid Interface Sci. 2002, 254, 402-405. [CrossRef] [PubMed]

17. Eo, M.; Baek, J.; Song, H.D.; Lee, S.; Yi, J. Quantification of electron transfer rates of different facets on single gold nanoparticles during catalytic reactions. Chem. Commun. 2013, 49, 5204-5206. [CrossRef] [PubMed]

18. Mahmoud, M.A.; Garlyyev, B.; El-Sayed, M.A. Controlling the catalytic efficiency on the surface of hollow gold nanoparticles by introducing an inner thin layer of Platinum or Palladium. J. Phys. Chem. Lett. 2014, 5, 4088-4094. [CrossRef] [PubMed]

19. Liang, F.; Chen, B. A review on biomedical applications of single-walled carbon nanotubes. Curr. Med. Chem. 2010, 17, 10-24. [CrossRef] [PubMed]

20. Zhou, X.; Liang, F. Application of graphene/grapheneoxide in biomedicine and biotechnology. Curr. Med. Chem. 2014, 21, 855-869. [CrossRef] [PubMed]

21. Liang, F.; Chen, R. Emerging assay platforms based on nanostructures. Curr. Nanosci. 2015, 11, 684. [CrossRef] 
22. Liang, F.; Chen, R. Functional nanomaterials for emerging biological applications. Curr. Nanosci. 2016, 12, 404. [CrossRef]

23. Zhang, H.; Watanabe, T.; Okumura, M.; Haruta, M.; Toshima, N. Catalytically highly active top gold atom on palladium nanocluster. Nat. Mater. 2012, 11, 49-52. [CrossRef] [PubMed]

24. Zhang, H.; Toshima, N. Glucose oxidation using Au-containing bimetallic and trimetallic nanoparticles. Catal. Sci. Technol. 2013, 3, 268-278. [CrossRef]

25. Zhang, H.; Lu, L.; Kawashima, K.; Okumura, M.; Haruta, M.; Toshima, N. Synthesis and catalytic activity of crown jewel-structured (IrPd)/Au trimetallicnanoclusters. Adv. Mater. 2015, 27, 1383-1388. [CrossRef] [PubMed]

26. Han, Y.; Yang, X.; Liu, Y.; Ai, Q.; Liu, S.; Sun, C.; Liang, F. Supramolecular controlled cargo release via near infrared tunable cucurbit[7]uril-gold nanostars. Sci. Rep. 2016, 6, 22239. [CrossRef] [PubMed]

27. Shu, T.; Su, L.; Wang, J.; Lu, X.; Liang, F.; Li, C.; Zhang, X. Value of the debris of reduction sculpture: Thioletching of $\mathrm{Au}$ nanoclusters for preparing water-soluble and aggregation-induced emission-active $\mathrm{Au}(\mathrm{I})$ complexes as phosphorescent copper ion sensor. Anal. Chem. 2016, 88, 6071-6077. [CrossRef] [PubMed]

28. Jana, N.R.; Gearheart, L.; Murphy, C.J. Seeding growth for size control of 5-40 nm diameter gold nanoparticles. Langmuir 2001, 17, 6782-6786. [CrossRef]

29. Rodríguez-Fernández, J.; Pérez-Juste, J.; García de Abajo, F.J.; Liz-Marzán, L.M. Seeded growth of submicron Au colloids with quadrupoleplasmonresonance modes. Langmuir 2006, 22, 7007-7010. [CrossRef] [PubMed]

30. Fang, J.; Zhang, B.; Yao, Q.; Yang, Y.; Xie, J.; Yan, N. Recent advances in the synthesis and catalytic applications of ligand-protected, atomically precise metal nanoclusters. Coord. Chem. Rev. 2016, 322, 1-29. [CrossRef]

31. Quaresma, P.; Soares, L.; Contar, L.; Miranda, A.; Osorio, I.; Carvalho, P.A.; Franco, R.; Pereira, E. Green photocatalytic synthesis of stable Au and Ag nanoparticles. Green Chem. 2009, 11, 1889-1893. [CrossRef]

32. Nigra, M.M.; Ha, J.M.; Katz, A. Identification of site requirements for reduction of 4-nitrophenol using gold nanoparticle catalysts. Catal. Sci. Technol. 2013, 3, 2976-2983. [CrossRef]

33. Zeng, J.; Zhang, Q.; Chen, J.; Xia, Y. A comparison study of the catalytic properties of Au-based nanocages, nanoboxes, and nanoparticles. Nano Lett. 2010, 10, 30-35. [CrossRef] [PubMed]

34. Lim, B.; Xia, Y. Metal nanocrystals with highly branched morphologies. Angew. Chem. Int. Ed. 2011, 50, 76-85. [CrossRef] [PubMed]

35. Briggs, B.D.; Li, Y.; Swihart, M.T.; Knecht, M.R. Reductant and sequence effects on the morphology and catalytic activity of peptide-capped Au nanoparticles. ACS Appl. Mater. Interfaces 2015, 7, 8843-8851. [CrossRef] [PubMed]

36. Copéret, C.; Estes, D.P.; Larmier, K.; Searles, K. Isolated surface hydrides: Formation, structure, and reactivity. Chem. Rev. 2016, 116, 8463-8505. [CrossRef] [PubMed]

37. Juárez, J.; Cambón, A.; Goy-López, S.; Topete, A.; Taboada, P.; Mosquera, V. Obtention of metallic nanowires by protein biotemplating and their catalytic application. J. Phys. Chem. Lett. 2010, 1, 2680-2687. [CrossRef]

38. Yamamoto, H.; Yano, H.; Kouchi, H.; Obora, Y.; Arakawa, R.; Kawasaki, H. N,N-Dimethylformamide-stabilized gold nanoclusters as a catalyst for the reduction of 4-nitrophenol. Nanoscale 2012, 4, 4148-4154. [CrossRef] [PubMed]

39. Zhang, J.; Chen, G.; Chaker, M.; Rosei, F.; Ma, D. Gold nanoparticledecorated ceria nanotubes with significantly high catalytic activity for the reduction of nitrophenol and mechanism study. Appl. Catal. B 2013, 132, 107-115. [CrossRef]

40. Lee, J.; Park, J.C.; Song, H. A nanoreactor framework of a $\mathrm{Au} @ \mathrm{SiO}_{2}$ yolk/shell structure for catalytic reduction of $p$-Nitrophenol. Adv. Mater. 2008, 20, 1523-1528. [CrossRef]

41. Liu, R.; Liu, J.; Kong, W.; Huang, H.; Han, X.; Zhang, X.; Liu, Y.; Kang, Z. Adsorption dominant catalytic activity of a carbon dots stabilized gold nanoparticles system. Dalton Trans. 2014, 43, 10920-10929. [CrossRef] [PubMed]

42. He, R.; Wang, Y.C.; Wang, Z.; Liu, G.; Zhou, W.; Wen, L.; Li, Q.; Wang, X.; Chen, X.; Zeng, J.; et al. Facile synthesis of pentacle gold-copper alloy nanocrystals and their plasmonic and catalytic properties. Nat. Commun. 2014, 5, 4327. [CrossRef] [PubMed]

43. Huang, T.; Meng, F.; Qi, L. Facile Synthesis and one-dimensional assembly of cyclodextrin-capped gold nanoparticles and their applications in catalysis and surface-enhanced ramanscattering. J. Phys. Chem. C 2009, 113, 13636-13642. [CrossRef] 
44. Premkumar, T.; Geckeler, K.E. Cucurbit[7]uril as a tool in the green synthesis of gold nanoparticles. Chem. Asian J. 2010, 5, 2468-2476. [CrossRef] [PubMed]

45. Barrow, S.J.; Kasera, S.; Rowland, M.J.; del Barrio, J.; Scherman, O.A. Cucurbituril-based molecular recognition. Chem. Rev. 2015, 115, 12320-12406. [CrossRef] [PubMed]

46. Guo, B.; Han, G.; Li, M.; Zhao, S. Deposition of the fractal-like gold particles onto electrospun polymethylmethacrylate fibrous mats and their application in surface-enhanced Raman scattering. Thin Solid Films 2010, 518, 3228-3233. [CrossRef]

47. Personick, M.L.; Langille, M.R.; Zhang, J.; Harris, N.; Schatz, G.C.; Mirkin, C.A. Synthesis and isolation of $\{110\}$-faceted gold bipyramids and rhombic dodecahedra. J. Am. Chem. Soc. 2011, 133, 6170-6173. [CrossRef] [PubMed]

(C) 2017 by the authors; licensee MDPI, Basel, Switzerland. This article is an open access article distributed under the terms and conditions of the Creative Commons Attribution (CC BY) license (http:/ / creativecommons.org/licenses/by/4.0/). 